\title{
REFLEXÕES ACERCA DA EDUCAÇÃO AMBIENTAL CONSCIENTIZADA EM AÇÕES EFETIVAS E PRÁTICAS.
}

\section{Maurício Dias Marques}

\section{Lucas Seolin Dias ${ }^{2}$}

RESUMO: Nos últimos anos muito se tem ouvido sobre educação ambiental. Este trabalho tem como objetivo salientar que, como qualquer outra modalidade de educação, a educação ambiental não deixa de ser um processo mediante o qual as pessoas são ensinadas ou aprendem por si como lidar com a natureza. Foram utilizados artigos e livros como forma de refletir o que compreende a verdadeira educação ambiental em termos de resultado. Observou-se, de forma refletida, que a natureza, tal qual fora criada, contém tudo extremamente perfeito, em pleno funcionamento e condições de interação dos recursos: hídricos, florestais, animais e minerais. O homem, porém, na ganância socioeconômica, destrói aos poucos a natureza e não deixa tempo para reposição de seus recursos. Conclui-se que precisamos nos conscientizar cada vez mais que nossas ações, nosso fazer, quer individual, quer coletivo, são imprescindíveis para amenizar os problemas ambientais e estabelecer condições para que nossa geração e as futuras tenham sobrevivência na terra. É preciso agir, não apenas conhecer os problemas.

\footnotetext{
1 Especialista em Direito Tributário e Administração Empresarial. Bacharel em Direito, Administração, Ciências Contábeis, Teologia. Licenciado em Letras. Professor da Faculdade de Ciências Contábeis de Lucélia. E-mail: mdmarques1985@gmail.com.

2 Especialista em Gestão de Marketing e Comunicação Integrada. Bacharel em Direito. Acadêmico de Comunicação pela UEL - Universidade Estadual de Londrina. E-mail: lucas_seolin@yahoo.com.br.
} 
Palavras-chave: Educação ambiental. Natureza. Ações ambientais. Conscientização, ações individuais e coletivas.

\section{INTRODUÇÃO}

Todos os seres vivos são alvo de um processo educativo. Os animais aprendem por instinto e/ou estímulo de seus "pais". O ser humano aprende em casa, na rua, na escola, na igreja. A aprendizagem consiste em saber, fazer, ser e conviver. Como seres humanos, estamos aprendendo ou sendo educados em sociedade, de tal forma que aprendemos não apenas nas escolas ou pela transferência de conhecimentos, mas aprendemos com a vida.

Aprender com a vida, realizar tudo que for útil e proveitoso para preservação da natureza é questão primordial para se construir a "educação ambiental" adequada e com resultados. Lembremos que essa educação deve ser promovida nos três estágios da vida: infantil, juvenil e adulta.

A intenção deste trabalho é fazer uma reflexão sobre a educação ambiental e levantar questionamentos sobre a falta de ações, apesar de muito diálogo sobre as questões que envolvem o meio ambiente e o desenvolvimento sustentável. É fundamental, portanto, pensarmos sobre a educação ambiental não só nas escolas e universidades, mas em todos os setores da sociedade e, em educação praticada por condutas e ações individuais e coletivas.

\section{DESENVOLVIMENTO}

\subsection{Educação}

Antes de se falar em educação ambiental, temos que refletir um pouco sobre a educação em geral. Para tanto, é bom lembrar que todo o ser vivente (homens ou animais) sofre um processo educativo. Os animais aprendem por extinto ou estímulo de seus "pais"; os humanos, através de um processo educativo social iniciado na família, em casa, mas prosseguindo o aprendizado, ao longo da vida, no quintal, na rua, na oficina, na escola, na empresa, na igreja, etc. 
Ainda que em grupos humanos bem simples, ocorrem trocas sociais que socializam crianças e adolescentes. Esse processo de socialização tem por alvo aquilo que a sociedade (o grupamento humano) idealiza como bom e aceitável ao grupo.

Carlos Rodrigues Brandão, 1998, p. 22/23, expressa:

\begin{abstract}
Cada tipo de grupo humano cria e desenvolve situações, recursos e métodos empregados para ensinar às crianças, aos adolescentes, e também aos jovens e mesmo aos adultos, o saber, a crença e os gestos que o tornarão um dia o modelo de homem ou mulher que o imaginário de cada sociedade - ou mesmo de cada grupo mais específico, dentro dela - idealiza, projeta e procura realizar. (p. 22). Nunca as pessoas crescem a esmo e aprendem ao acaso. (p. 23).
\end{abstract}

Portanto, a educação dá-se pela transferência de saber de uma geração para outra. A educação aparece sempre que se conduz na aventura de ensinar-e-aprender.

Recorrendo à filosofia grega, podemos salientar que a educação é uma trajetória de amadurecimento e formação, cujo produto final é o adulto educado. Desde seu nascimento até sua morte, o ser humano pode ser comparado como o barro nas mãos do oleiro, que o modela conforme sua intenção. Deus, o oleiro autor da vida, quer modelar o homem para que este seja belo física, mental, moral e espiritualmente, mas muitas vezes o homem não aceita a intervenção e deixa-se levar por suas próprias convicções que podem trazer-Ihe malefício.

Aqui queremos salientar a educação como um processo contínuo de aprendizado teórico e prático que se adquire pela vivência, experiência e imitação de exemplos, não a educação formal que ocorre nas escolas, já que esta é apenas um dos canais ou instrumentos para a educação.

Os mais conhecidos dicionários da língua portuguesa assim definem "educação":

Ação e efeito de educar, de desenvolver as faculdades físicas, intelectuais e morais da criança e, em geral, do ser humano; disciplinamento, instrução, ensino (Dicionário Contemporâneo da Língua Portuguesa, Caldas Aulete).

Ação exercida pelas gerações adultas sobre as gerações jovens para adaptá-las à vida social; trabalho sistematizado, seletivo, orientador, pelo qual nos ajustamos à vida, de acordo com as necessidades ideais e propósitos dominantes; ato ou efeito de educar; aperfeiçoamento integral de todas as faculdades humanas, polidez, cortesia (Pequeno Dicionário Brasileiro de Língua Portuguesa, Aurélio Buarque de Holanda).

A Lei de Diretrizes e Bases da Educação Nacional, Lei 9.394/96, assim define a educação e a que serve: 


\begin{abstract}
Art. 1을 A educação abrange os processos formativos que se desenvolvem na vida familiar, na convivência humana, no trabalho, nas instituições de ensino e pesquisa, nos movimentos sociais e organizações da sociedade civil e nas manifestações culturais.

Art. 20 A educação, dever da família e do Estado, inspirada nos princípios de liberdade e nos ideais de solidariedade humana, tem por finalidade o pleno desenvolvimento do educando, seu preparo para o exercício da cidadania e sua qualificação para o trabalho.
\end{abstract}

\title{
2.2 Uma visão ampla dos problemas ambientais
}

É certo que a população do planeta cresceu e cresce vertiginosamente. Mas, pior que isso, o agrupamento nas cidades gerou e vem gerando poluição do ambiente, por diversos fatores: pelo avanço da indústria, pelo consumismo, pela extinção da fauna e da flora, dentre outros problemas.

Ora, se Deus criou o mundo (a natureza) perfeito, equilibrado e organizado, o homem o destrói aos poucos, em nome do progresso, da tecnologia, da modernidade:

a) Retira petróleo do subterrâneo, mas nada coloca em seu lugar, o que provoca catástrofes naturais, como terremotos e maremotos, pois a natureza responde, tem que adaptar-se.

b) Expande as cidades e para tal retira mata ciliar, desfaz morros, canaliza riachos e rios, impermeabiliza o solo, e a natureza responde com inundações e erosões.

c) Os aglomerados urbanos expelem seu lixo impropriamente, gerando poluição das águas.

d) Em nome da tecnologia, constrói usinas hidroelétricas, sem atentar para a destruição do equilíbrio ambiental que elas provocam; constrói usinas nucleares, sem atentar para o risco de contaminação; avança na construção de foguetes e armas nucleares, sem se perturbar com a consequência de seus atos, pensando talvez que os construtores e idealizadores estarão livres da poluição.

e) Suas indústrias processam matérias-primas retiradas da natureza e expelem resíduos poluentes, lançados no ar e na água sem qualquer precaução ou sem incomodar-se com o que ocorrerá. 
f) Pela ação humana crescem exageradamente os insetos parasitas, presentes na criação para controle ambiental.

Chama-nos atenção, por exemplo, as anotações do Caderno de Educação Ambiental da Secretaria do Meio Ambiente do Estado de São Paulo, de 1997, p. 97/98:

\begin{abstract}
Existem cerca de 400 usinas nucleares no nosso planeta, cada uma produzindo lixo radioativo com meia-vida de até 24 mil anos. A tecnologia nuclear tem sido empregada como se alguém soubesse, com grande segurança, como proteger as usinas de um desastre catastrófico, como desativá-las sem risco quando sua vida produtiva termina, e como manter seus resíduos longe da biosfera e hidrosfera por dezenas de milhares de anos. E ninguém sabe essas coisas; no entanto, procede-se supondo um conhecimento muito maior do que aquele que realmente se tem. (p. 97) $[\ldots]$

Ninguém sabe como uma bactéria, um vírus ou uma erva manipulados geneticamente podem comportar-se ao se espalharem nos sistemas interconectados e equilibrados da biosfera. Ninguém sabe quais serão todos os efeitos biológicos, econômicos e sociais da produção de chocolate em laboratórios, fruto da implantação de bactérias com genes de cacau, que dispensará o seu cultivo nos trópicos. Ninguém pensou no que significará o fato de algumas pessoas terem poder sobre a informação genética e outras não. (p. 98)
\end{abstract}

Estes são apenas alguns dos problemas que o homem gerou para si próprio.

Escrevendo para a Revista Ponto de Vista, Volume 4, p. 66, Eduardo Vaz de Melo, no artigo "Educação Ambiental: Um olhar sobre a teoria e a prática", assim se expressa:

Os padrões dominantes de produção e consumo estão alterando o clima, degradando o meio ambiente, esgotando os recursos naturais e causando a extinção massiva das espécies. O aumento dramático da população tem incrementado as pressões sobre os sistemas ecológicos e sobrecarregado os sistemas sociais. A injustiça, a pobreza, a ignorância, a corrupção, o crime, a violência e os conflitos armados intensificaram o sofrimento do mundo. São necessárias mudanças fundamentais de atitudes, de valores e de estilos de vida.

Passamos a subjugar a natureza aos nossos próprios interesses, apropriando-nos de seus recursos sem considerar que o tempo de recuperação da natureza segue um ciclo muito diferente e muito mais lento que nossa ganância consumista. Em razão disso estamos em crise ambiental nunca vista na história, eis que os "poderes" humanos levam a efeitos colaterais e consequências inevitáveis.

Veja o que é colocado pelo professor Mauro Guimarães, em seu artigo "Educação Ambiental: participação para além dos muros da escola", publicado no livro "Vamos Cuidar do Brasil - Conceitos e Práticas em Educação Ambiental na Escola” (2007, p. 87): 


\begin{abstract}
Na racionalidade que constitui e é constituída pela modernidade, o que prevalece são os interesses individuais/particulares sobre as necessidades comuns, coletivas, do conjunto. Essa prevalência justifica-se por essa postura individualista e antropocêntrica - quando a humanidade se vê como o centro, e tudo que está ao seu redor existe para atender aos seus interesses. Essas posturas, somadas à competição exacerbada entre indivíduos, classes sociais e nações, à acumulação privada de um bem público que é o meio ambiente, à acumulação ampliada e concentração da riqueza, entre outras, intensificou tremendamente a exploração do meio ambiente e o distanciamento entre os seres humanos dessa sociedade urbanoindustrial e a natureza, o que produz a degradação de ambos: sociedade e natureza.
\end{abstract}

\title{
2.3 Educação Ambiental
}

Poderíamos iniciar nossa abordagem sobre a Educação Ambiental com a seguinte citação:

A educação ambiental marca uma nova função social da educação, não constitui apenas uma dimensão, nem um eixo transversal, mas é responsável pela transformação da educação como um todo, em busca de uma sociedade sustentável. (LUZZI, 2005, p. 399.)

A Educação Ambiental tem um campo abrangente, porquanto vem sendo implementada através de pesquisas, análises e procura de conscientização sobre o conhecimento e obrigações com o meio ambiente, visando preparar o ser humano para a preservação da natureza e para o uso racional e sustentável dos recursos naturais.

Essa conscientização pode ser melhor compreendida nos dizeres da professora Ana Mansoldo, no artigo publicado na Revista Ecológica Integral no 29, p. 24:

Educação para conscientização é diálogo, um encontro de sujeitos interlocutores que buscam juntos o conhecimento. E conhecimento não se dá por transferência de saber, por mera informação, mas pela compreensão das causas e consequências de cada ação individual, repercutindo no coletivo.

$[\ldots]$

O sujeito educado para consciência de si e do mundo age espontaneamente pela redução de supérfluos, pela destinação adequada do lixo, pelo respeito às plantas, aos rios e aos animais, pelo cuidado consigo e com seu semelhante, como simples consequência de seu novo olhar para o mundo.

É certo que o processo de conscientização é de difícil implantação. Veja o que deixa à reflexão o professor Carlos Frederico B. Loureiro, em seu artigo "Educação Ambiental Crítica: contribuições e desafios", apresentado no livro "Vamos Cuidar do Brasil - Conceitos e Práticas em Educação Ambiental na Escola" (2007, p. 70): 


\begin{abstract}
a possuem, de se ensinar aos que nada sabem. Para a educação ambiental crítica, a emancipação é a finalidade primeira e última de todo o processo educativo que visa à transformação de nosso modo de vida; a superação das relações de expropriação, dominação e preconceitos; a liberdade para conhecer e gerar cultura tornando-nos autônomos em nossas escolhas.
\end{abstract}

$\mathrm{Na}$ realidade, de nada adianta encher a "internet", intensificar publicidades nos meios de comunicação de massa (rádio, jornais, revistas, TV), com vistas a promover a educação ambiental, se não houver ações. Apenas boas intenções não valerão nada, nem modificarão as estruturas da formação da civilização mundial, nacional, local, etc. É interessante perceber que governos, organizações, pessoas, até aproveitam o assunto para tirar proveito econômico. O que se precisa de fato são ações que se realizem do mais alto escalão político-social até o indivíduo. Veja a analogia que fez CHIAVENATO,1989, p.7:

Da mesma forma que existe uma indústria que polui e ao mesmo tempo fatura imensamente, fabricando e vendendo a tecnologia da despoluição, há os que se aproveitam de um assunto em moda e encomendam livros com uma urgência terrível: é preciso chegar ao mercado antes da concorrência.

Como estamos pensando o homem como um ser social por excelência, que vive em grupos e interage com o meio físico e social em que está situado, podemos depreender que a educação ambiental deve ser processada não apenas nas escolas, mas no próprio convívio social.

O homem deve compreender que faz parte da natureza, nela foi colocado para viver de seus recursos e cuidá-la, tornando a vivência do planeta perfeitamente viável para todos: fauna, flora e humanos. Há possibilidade sim de convivência harmônica dos elementos da natureza desde que o homem, como ser racional que é, não se aproprie dos recursos naturais como um "louco" e "destruidor". Eis o que já apontava o Caderno de Educação Ambiental da Secretaria do Meio Ambiente do Estado de São Paulo, de 1997 (páginas indicadas no texto):

Os seres humanos não são vítimas, nem senhores da natureza, mas guardiões de algo que não deve ser explorado irracionalmente, nem permanecer totalmente intocado. Compreender isso é necessário para promover as ações, invenções e organizações sociais que respeitem a viabilidade, estabilidade e produtividade, tanto da sociedade humana como dos sistemas naturais nos seus milhares de interações. (p. 22) $[\ldots]$ 


\begin{abstract}
Os homens estão apenas começando a aprender como projetar uma economia complexa, moderna, industrial e de alta produtividade, que obedeça aos requisitos planetários referentes aos ciclos. Rejeitos orgânicos vindos do campo e das cidades podem ser compostados e devolvidos ao solo; metais, papel, vidro e plásticos podem ser recuperados, reciclados e reutilizados; produtos químicos diferentes podem ser criados, usados ou introduzidos em outros processos de manufatura, frequentemente com grandes benefícios tanto econômicos quanto ambientais. (p. 40)

[...]

Nós temos uma capacidade enorme de destruir ou construir a fecundidade e a estabilidade do nosso ambiente. Numa média global, os seres humanos estão destruindo mais do que construindo. Em muitos locais, a erosão do solo dá-se mais rapidamente do que a sua formação, a destruição das florestas é mais rápida do que o seu crescimento, a água subterrânea é bombeada em tempo mais curto do que a sua reposição e os pastos são consumidos em ritmo superior ao do seu crescimento. (p. 63/64)

[...]

Alta produtividade, tecnologia moderna e desenvolvimento econômico podem coexistir com um ambiente saudável. E necessitam mesmo coexisitir, caso contrário, o desenvolvimento não será sustentável. (p. 82)
\end{abstract}

A interligação do homem com a natureza, a evolução científico-tecnológica da mente humana e o estabelecimento de meios mais apropriados e facilitados de se viver confortavelmente, têm seu preço. O homem não pode usar da natureza deteriorando-a, esgotando-a, menosprezando-a. Deve saber comportar-se dentro de um conjunto maior do qual é o expoente capaz de manobras para o bem ou para o mau. Essa reflexão, a par do que já foi dito e citado acima, torna-se essencial. Veja a conclusão a que chega Samuel Mugel Branco (1988, p. 21):

Em resumo, o homem, quer queira quer não, depende da existência de uma natureza rica, complexa e equilibrada em torno de si. Ainda que ele se mantenha isolado em prédios de apartamentos, os ecossistemas naturais continuam constituindo o seu meio ambiente. A morte desses ecossistemas representará a morte do planeta.

Entende-se por educação ambiental a conscientização humana a respeito das necessidades e obrigações com o meio ambiente. Pela educação ambiental o homem é preparado para preservar a natureza, fazendo uso sustentável de seus recursos. Esse processo pode ser feito através das escolas, da "internet", dos meios de divulgação (rádio, jornais, TV, revistas, etc.), das empresas, e também indivíduo a indivíduo (boca a boca), o que é mais eficaz. O que nos parece faltar é maior mobilização do poder público e das instituições de ensino, para que ações de conscientização sejam efetivamente bem trabalhadas. 
A educação ambiental no Brasil está disciplinada pela Lei 9.795/1999, a qual dá a definição, estabelece os objetivos e até propõe a educação ambiental não formal, como podemos ver nos artigos transcritos a seguir:

LEI N ${ }^{\circ}$ 9.795, DE 27 DE ABRIL DE 1999. (Dispõe sobre a educação ambiental, institui a Política Nacional de Educação Ambiental e dá outras providências).

O PRESIDENTE DA REPÚBLICA Faço saber que o Congresso Nacional decreta e eu sanciono a seguinte Lei:

CAPÍTULO I

DA EDUCAÇÃO AMBIENTAL

Art. $1^{\circ}$ Entendem-se por educação ambiental os processos por meio dos quais 0 indivíduo e a coletividade constroem valores sociais, conhecimentos, habilidades, atitudes e competências voltadas para a conservação do meio ambiente, bem de uso comum do povo, essencial à sadia qualidade de vida e sua sustentabilidade.

Art. $2^{\circ} \mathrm{A}$ educação ambiental é um componente essencial e permanente da educação nacional, devendo estar presente, de forma articulada, em todos os níveis e modalidades do processo educativo, em caráter formal e não formal.

Art. $3^{\circ}$ Como parte do processo educativo mais amplo, todos têm direito à educação ambiental, incumbindo:

I - ao Poder Público, [...]

II - às instituições educativas, [...]

III - aos órgãos integrantes do Sistema Nacional de Meio Ambiente - Sisnama, [...]

IV - aos meios de comunicação de massa, [...]

$V$ - às empresas, entidades de classe, instituições públicas e privadas, [...]

$\mathrm{VI}$ - à sociedade como um todo, [...]

[...]

Art. 5 São objetivos fundamentais da educação ambiental:

I - o desenvolvimento de uma compreensão integrada do meio ambiente em suas múltiplas e complexas relações, envolvendo aspectos ecológicos, psicológicos, legais, políticos, sociais, econômicos, científicos, culturais e éticos;

II - a garantia de democratização das informações ambientais;

III - o estímulo e o fortalecimento de uma consciência crítica sobre a problemática ambiental e social;

IV - o incentivo à participação individual e coletiva, permanente e responsável, na preservação do equilíbrio do meio ambiente, entendendo-se a defesa da qualidade ambiental como um valor inseparável do exercício da cidadania;

V - o estímulo à cooperação entre as diversas regiões do País, em níveis micro e macrorregionais, com vistas à construção de uma sociedade ambientalmente equilibrada, fundada nos princípios da liberdade, igualdade, solidariedade, democracia, justiça social, responsabilidade e sustentabilidade;

VI - o fomento e o fortalecimento da integração com a ciência e a tecnologia;

VII - o fortalecimento da cidadania, autodeterminação dos povos e solidariedade como fundamentos para o futuro da humanidade.

[...]

Seção III

Da Educação Ambiental Não-Formal

Art. 13. Entende-se por educação ambiental não formal as ações e práticas educativas voltadas à sensibilização da coletividade sobre as questões ambientais e à sua organização e participação na defesa da qualidade do meio ambiente. 
Educação ambiental deve ser promovida de maneira formal e informal. Seu alvo é a transformação social, pois para se conservar os recursos naturais, todos os integrantes da sociedade devem ter sua parcela de contribuição e todos estarem dispostos à cooperação mútua, mudando as formas de pensar e agir individualmente.

Catástrofes advindas das ações humanas nas últimas décadas despertaram a atenção para estudos, formas de contenção e conscientização da preservação da natureza. Organismos internacionais discutem educação ambiental; governos lançam programas de educação ambiental; o tema mais em voga na atualidade é educação ambiental. Mas, qual o fruto de todo esse esforço, já que em nome da soberania não se quer abrir mão de prerrogativas?

Diria que cada governo mundial, cada governo local, cada empresa industrial, cada comunidade, sente-se competente para promover seu progresso, sem se importar com seu vizinho, sem se preocupar com o global, embora se pense em um mundo globalizado.

Lea Tiriba, em seu artigo "Reinventando relações entre seres humanos e natureza nos espaços de educação infantil", no livro "Vamos Cuidar do Brasil - Conceitos e Práticas em Educação Ambiental na Escola" (2007, p. 220), proclama:

\begin{abstract}
Vivemos uma situação de emergência planetária, em que está clara a possibilidade de que a espécie humana concretize um processo de autodestruição, criando condições socioambientais insuportáveis a sua sobrevivência e de outras espécies na Terra. Ludibriada pelo mito da natureza infinita, auxiliada por sua inteligência e onipotência e ensandecida pelo desejo de possuir e consumir, a civilização ocidental criou, nos últimos 200 anos, um modelo de desenvolvimento que não está voltado para o bem-estar e felicidade dos povos e espécies, mas para os interesses de mercado. Centrado na produção e consumo de bens, orientado para gerar lucro, este modelo - capitalista, urbano, industrial, patriarcal - vem gerando, ao mesmo tempo, desequilíbrio ambiental, desigualdade social e sofrimento pessoal.
\end{abstract}

De nada adianta pregar ou ensinar nos bancos escolares as formas corretas de se proceder com a natureza, se a prática é outra. O discurso é um, mas as atitudes a ele não correspondem. Assim é que pensamos que a educação ambiental formal pouco ou quase nada resolve; discussões em torno do assunto também trazem pouco proveito. $O$ que se precisa são ações educativas.

O professor Mauro Guimarães, já mencionado acima, traz a seguinte reflexão (2007, p. 91): 
Acreditamos que uma educação ambiental, capaz de contribuir no enfrentamento da crise socioambiental que vivenciamos, é aquela que faz do ambiente educativo, espaços de participação, em que a aprendizagem se dá em um processo de construção de conhecimentos vivenciais, que experiencie ações que tenham a intencionalidade, como uma ação política, de intervir na realidade transformando-a.

Eis o que pondera a professora Isabel Cristina Moura Carvalho, em seu artigo "O sujeito ecológico: a formação de novas identidades culturais e a escola", publicado no livro "Vamos Cuidar do Brasil - Conceitos e Práticas em Educação Ambiental na Escola" (2007, p. 137/138):

Faz-se necessário destacar que, mesmo para quem se identifica com a proposta ecológica, há uma permanente negociação intrapessoal, interpessoal e política em torno das decisões do dia-a-dia. Nesse sentido, a busca por ter sua vida guiada pelos ideais de um sujeito ecológico não isenta as pessoas das contradições, conflitos e negociações que sempre acontecem entre nossa realidade imperfeita e os nossos melhores ideais. (p. 137)

É preciso considerar que há também na sociedade pessoas e grupos que absolutamente não se identificam com os apelos de uma existência ecológica. Para estes, os ideais preconizados pelo sujeito ecológico podem ser vistos como ingênuos, anacrônicos, pouco práticos, "malucos"; enfim, de alguma forma não são reconhecidos como orientadores do que esses grupos consideram uma vida desejável e boa. Como vivemos numa sociedade plural, os valores ecológicos não são a única orientação disponível para a vida pessoal e coletiva. [...] Basta observar a valorização de modos de vida, que poderíamos chamar, para contrastar com a visão ecológica e pacifista, de modos "bélicos" de viver e conviver (p. 137/138).

[...]

Esses elementos existem em nossa cultura e estão bem vivos nos famosos ditados "salve-se quem puder", "cada um por si", "a lei do mais forte" e tantos outros em que poderíamos ver a apologia de uma ação que desconsidera o bem comum. São alguns exemplos de modos de pensar nada ecológicos, mas bastante disseminados e igualmente formadores de subjetividades. Conclusão, nem todo mundo está a ponto de adotar uma orientação ecológica em sua vida (p. 138).

Veja o que observa Rachel Trajber, no artigo "Cidadania e Consumo

Sustentáveis: nossas escolhas em ações conjuntas", no livro "Vamos Cuidar do Brasil Conceitos e Práticas em Educação Ambiental na Escola" (2007, p. 144/145):

Para garantir qualidade de vida para a nossa e para as futuras gerações, precisamos mudar valores e atitudes individuais e coletivas, a começar por viver com o planeta em mente. Acreditamos que um pensamento crítico mais responsável e solidário, por ser comprometido com o coletivo, e voltado para a simplicidade, por ser menos individualista, consumista e competitivo, pode nos levar, e aos nossos jovens estudantes, a uma postura que permita um presente e um futuro sustentáveis.

[...]

Sabemos que nossa sobrevivência depende do consumo, da existência de alimentos, de uma fonte constante de energia, da disponibilidade de matérias- 
primas para os processos produtivos bem como da capacidade dos vários resíduos que produzimos serem absorvidos sem se constituírem em ameaça. Contudo, para assegurar a existência das condições favoráveis à vida, teremos que produzir e consumir de acordo com o que a Terra pode fornecer.

Paulo Blikstein, escrevendo sob o título "As novas tecnologias na educação ambiental: instrumentos para mudar o jeito de ensinar e aprender na escola", no livro "Vamos Cuidar do Brasil - Conceitos e Práticas em Educação Ambiental na Escola" (2007, p. 156), afirma:

Sabemos que o primeiro passo para qualquer grande transformação é mudar o que as pessoas pensam e, felizmente, isso está acontecendo com a educação. Muita gente já sabe como deve ser, mas ninguém sabe como transformar essa visão em realidade.

Devemos refletir que a vida moderna, com os equipamentos, instrumentos, objetos construídos a partir de matéria-prima que não se degenera (plásticos, chumbo, etc.), a facilidade e comodismo de se viver em grandes aglomerados urbanos, tudo isso leva a impactos ambientais sem precedentes. Pode parecer utopia, mas se quiséssemos de fato limpar o planeta, se quiséssemos eliminar problemas de poluição, teríamos que voltar à vida primitiva, vida no campo, uso de animais, carroças ou bicicletas para locomoção, não utilização da alta tecnologia que se faz à custa da natureza. Mas, ninguém quer isso!

Então, ao menos, teremos que ter a consciência de minimização dos problemas ambientais. Nossa sociedade de consumo deve entender que só poderia consumir o essencialmente necessário e trocar produtos poluentes, que mancham, corrompem, maculam o ambiente, por produtos recicláveis, que possam ser tratados para reaproveitamento, que não oferecem riscos ao ambiente.

Para tanto, ainda que muito já se tenha falado, escrito, debatido, discutido, apresentamos algumas formas/exemplos de educação ambiental que deveriam ser promovidas, aprendidas e, principalmente, colocadas em prática, eis que a educação ambiental só será eficaz se o saber aprendido for completado com o "saber fazer", com ações integradas de todos para todos. 
É forçoso lembrar aqui o discurso da garota canadense de 12 anos, Severn Suzuki, representante das crianças em defesa do meio ambiente, que calou o mundo por 6 minutos na Eco 92, do qual coloco algumas frases para nossa reflexão:

- Se vocês não podem recuperar nada disso, então, por favor, parem de destruir! - Meu pai sempre diz: "Você é aquilo que faz, não aquilo que você diz".

- Vocês, adultos, nos dizem que nos amam. Eu desafio vocês. Por favor, façam as suas ações refletirem as suas palavras.

Os seres viventes com inteligência deveriam deixar de lado seu orgulho, poder, força, e passar a preocuparem-se com sua sobrevivência e, muito mais, a sobrevivência das futuras gerações. Não há interesse ideológico ou político em questões ambientais, é interesse geral, interesse crucial e urgente. Rápidas "ações” devem ser implementadas, repassadas, imitadas, mudando o comportamento de todos, procurando resgate, pelo menos em parte, do que já foi perdido. Veja o que nos faz refletir CHIAVENATO (1989, p. 25):

Ecologia é simplesmente vida. Isso está além de qualquer interesse ideológico ou político. O homem caminha rapidamente para o seu próprio extermínio. Classicamente, os cientistas acreditavam que a vida na Terra - e o próprio planeta - poderia durar mais oito bilhões de anos, quando a fusão do gás hélio, no Sol, a faria "esquentar" e "ferver", matando-nos. Hoje, apesar de a natureza nos ter programado para viver mais esses oito bilhões de anos, o próprio homem pode acabar com tudo a qualquer momento, em poucos minutos. Ou gradualmente, continuando a agressão ao meio ambiente, em cinquenta, cem, duzentos anos... É preciso lutar contra isso sem pudor, sem tentativas de acomodar essa luta a receitas ideológica. O que não elimina, evidentemente, a necessidade de uma transformação radical das estruturas sócioeconômicas para assegurar o sucesso e a sobrevivência.

É necessário mudança de comportamento. Nossos valores, tais quais a responsabilidade, o respeito mútuo, o compromisso, a solidariedade, devem ser pensados melhor e estimulados a uma visão global e de inclusão social. Se quisermos viver em um mundo melhor não podemos deixar para que outros iniciem as necessárias mudanças, mas nós mesmos, cada um, cada órgão, cada comunidade, cada governo, praticar ações de resgate ao meio ambiente:

a) No âmbito internacional 
Todos os governantes devem estar conscientes de que a natureza se esgota. As energias propulsoras da modernidade precisam ser energias renováveis. Não se pode trabalhar com tecnologia química/nuclear sem consequências. Não se pode, em nome da soberania, tolerar guerras e conflitos onde a devastação da natureza é o lema. O governante de cada país deve se conscientizar que ele e seu país vivem interligados com os demais e que, mesmo potente e glorioso, não pode menosprezar ou prejudicar os outros. A partir daí, os organismos internacionais deveriam aconselhar os governantes a:

- Aprender com os erros já cometidos, reparando-os.

- Prever e evitar desastres ambientais, principalmente quando irreversíveis.

- Utilizar energias renováveis, preterindo, reduzindo ou neutralizando a extração do petróleo.

- Proibir a utilização de armas químicas ou o desenvolvimento de equipamentos e obras que utilizem a energia nuclear.

- Promover ações conjuntas para reparação imediata no caso de acidentes nucleares e/ou acidentes que provoquem derramamento de combustíveis ou substâncias tóxicas na terra, atmosfera e mar.

- Cuidar das matas naturais em geral, precavendo contra queimadas ou desastres que as reduzam e acabem com os animais.

- Fiscalizar os recursos hídricos para evitar sua contaminação e/ou devastação.

- Destinar recursos financeiros para recuperação de grandes áreas degradadas.

b) No âmbito nacional

O governo brasileiro deve mudar conceitos e ter por alvo a preservação da natureza, não praticando ações contra a mesma. Deve promover campanhas que chamem atenção da população sobre os problemas ambientais e, muito mais, ser exemplo, demonstrando que o governo não está sendo causa desses problemas. Antes de construir uma obra pública não pensar apenas em interesse político, mas nos interesses da população e cuidado com a natureza. Assim, o governo deveria:

- Seguir orientações ambientais dos organismos internacionais;

- Manter vigilância policial constante e em nossas matas, florestas e rios;

- Assessorar os governos estaduais quando da construção de obras que envolvam dois ou mais Estados, com riscos ambientais; 
- Promover campanhas nacionais de educação ambiental, na mídia impressa, falada, televisiva.

c) No âmbito regional

Os governos estaduais devem promover ações exemplares de cuidado com a natureza. Ao realizar obras públicas, estudar previamente a afetação que elas trarão ao meio ambiente. Se realizadas em conjunto com outros Estados, a reunião de governos deve ser imprescindível e norteada à preservação da natureza.

d) No âmbito local

Cada prefeito municipal deve cuidar bem do território sob sua jurisdição. Cuidar da fauna e flora que ainda restam intocadas e promover ações de recuperação daquelas que, despreocupadamente, foram alvo de deterioração por outras administrações municipais. São ações de sua responsabilidade:

- Implementar políticas de reflorestamento, reciclagem e planejamento familiar;

- Planejar a extensão do território das cidades de maneira a não excluir a natureza;

- Intensificar a fiscalização sobre praças públicas;

- Fiscalizar cortes e replantio de árvores nas calçadas;

- Promover a reconstrução de faixa mínima de mata nas margens de rios e riachos;

- Ao autorizar novos loteamentos estar atento ao fato de que a derrubada de plantas nativas deve ser compensada com seu plantio em outro local;

- Ao construir estradas ou obras públicas, fazer estudos preliminares para evitar a erosão;

- Implantar um viveiro municipal para manter um banco de sementes e mudas, a fim de repor o verde;

- Implantar rede de tratamento de esgoto;

- Implantar a coleta seletiva do lixo e a formação de aterro sanitário para o lixo orgânico, com processos de compostagem.

e) No âmbito coletivo

Cada cidadão deve pensar coletivamente. Cada cidadão deve agir de maneira a não afetar a natureza em seu derredor, bem como noutro local. Cada qual deve cuidar de 
suas ações para com a natureza em conjunto com seu vizinho, com seu amigo, denunciando fatos que demandam prejuízo público coletivo no tocante a deterioração dos recursos naturais.

f) No âmbito das indústrias/empresas/agricultura

O empresário industrial, comercial, prestador de serviços ou promotor do agronegócio deve estar consciente de que sua produção não pode afetar o meio ambiente além do que este possa suportar. Portanto, deveria:

- Implementar sistemas de filtros em chaminés de queima de resíduos tóxicos;

- Tratar dos efluentes antes de deitá-los em rios ou riachos;

- Colocar estrategicamente recipientes para coleta seletiva do material descartado pelos funcionários;

- Instalar indústrias próximas aos recursos locais e renováreis, ao invés de depender de recursos distantes e não renováveis;

- Os agricultores deveriam conhecer e implantar organismos vivos de defesa, não fazendo uso de agrotóxicos em demasia ou desnecessariamente;

- Utilizar nutrientes naturais para a terra, como esterco; controlar as pragas e ervas daninhas pela rotatividade das lavouras.

g) No âmbito individual

Cada cidadão deve viver bem, mas sem trazer transtorno à natureza e aos seus semelhantes. Por isso suas ações devem seguir padrões já tão bem difundidos, não ficando só na teoria, mas fazendo:

- Seleção do lixo doméstico;

- Não jogar papéis, plástico ou qualquer material a esmo, na rua, na beira de estradas, etc., mas depositá-los em recipientes próprios, levados à reciclagem;

- Não jogar óleo saturado no esgoto;

- Não desperdiçar água e energia elétrica;

- Usar papel reciclado;

- Consumir produtos orgânicos;

- Adquirir roupas de algodão ou linho (mais naturais que as sintéticas);

- Andar a pé ou de bicicleta, ou utilizar veículo em grupo; 
- Plantar árvores no terreno de sua residência;

- Utilizar aquecimento solar nas residências.

\section{CONCLUSÃO}

Diante de tudo o que foi exposto, notadamente as ponderações dos autores que transcrevemos, podemos concluir que não estamos, de fato, fazendo ou promovendo educação ambiental. Simplesmente abordamos o assunto, discutimos muito, trazemos à reflexão a realidade presente e futura, porém, estamos longe de realizar ações individuais e conjuntas para implantar ou implementar uma educação ambiental de consciência, para promover mudança de comportamento, para promover auxílio mútuo para o bem comum da geração atual e das futuras gerações.

Se quisermos "salvar" o planeta e termos condições de sobrevida, devemos praticar tudo aquilo de que já estamos fartamente advertidos; devemos cuidar, cada um de nós, de nosso espaço físico, de nossa casa, de nossas rodovias, de nossa região, denunciando, participando, fazendo ações que interessam à preservação do meio ambiente. Alguns exemplos dessas ações foram colocados como condições para que cada líder, responsável, ou indivíduo, pratique a sua parte.

\section{REFERÊNCIAS}

BRANCO, Samuel Murgel. O Meio Ambiente em Debate. São Paulo: Moderna, 1988

BRANDÃO, Carlos Rodrigues. O que é educação. São Paulo: Brasiliense, Coleção Primeiros Passos, 280 ed., 1993.

BRASIL. Lei Federal oㅜ 9.394, de 1996. Estabelece as diretrizes e bases da educação nacional. DOU 23.12.1996. Disponível em http://www.planalto.gov.br/ccivil 03/leis//9394.htm. Acesso em 10/09/2013.

BRASIL. Lei Federal oํ 9.795, de 1999. Dispõe sobre a educação ambiental, institui a Política Nacional de Educação Ambiental e dá outras providências. DOU 28.04.1999. Disponível em http://www.planalto.gov.br/ccivil 03/leis/19795.htm . Acesso em 06/09/2013.

CHIAVENATO, Júlio José. O Massacre da Natureza. São Paulo: Moderna, 1989 (Coleção Polêmica) 
INFOESCOLA. Educação Ambiental. Disponível em http://www.infoescola.com/ecologia/educacao-ambientall. Acesso em 02/09/2013

JACOBI, Pedro. Educação Ambiental, Cidadania e Sustentabilidade. Artigo publicado no Cadernos de Pesquisa, n. 118, mp. a1 rç8o9/-220050,3 março/ 2003 189. Disponível em http://www.scielo.br/pdf/cp/n118/16834.pdf. Acesso em 02/09/2013

LUZZI, Dias. Educação Ambiental: Pedagogia, Política e Sociedade. In: PHILIPPI JR, A. e PELICIONI, M. C. F. (editores). Educação Ambiental e Sustentabilidade. Barueri, SP: Manole, 2005.

MANSOLDO, Ana. Como fazer educação (ambiental). Revista Ecológica Integral n² 29. Disponível em http://www.ecologiaintegral.org.br/Artigo01AnaMansoldo.pdf. Acesso em 16/09/2013.

MELO, Eduardo Vaz de. Educação Ambiental: um olhar sobre a teoria e a prática. Revista Ponto de Vista, vol.4. Disponível em

http://www.coluni.ufv.br/revista/docs/volume04/educacaoAmbiental.pdf. Acesso em 02/09/2013.

PORTAL EMBRAPA. Como promover educação ambiental com adoção de práticas agrícolas nas escolas. Disponível em http://hotsites.sct.embrapa.br/prosarural/programacao/2011/ como-promover-educacao-ambiental-com-adocao-de-praticas-agricolas-nas-escolas. Acesso em $28 / 08 / 2013$

SÃO PAULO (Estado), Secretaria do Meio Ambiente. Cadernos de Educação Ambiental Conceitos para se fazer Educação Ambiental. 2 ed. São Paulo: A Secretaria, 1997

SILVEIRA, Paula. Educação Ambiental - Como Fazer? Disponível em http://www.sociosistemas.com/Educacao\%20Ambiental.pdf. Acesso em 02/09/2013.

VAMOS CUIDAR DO BRASIL: conceitos e práticas em educação ambiental na escola. [Coordenação: Soraia Silva de Melo, Rachel Trajber]. Brasília: Ministério da Educação, 2007. Disponível em http://portal.mec.gov.br/dmdocuments/publicacao3.pdf. Acesso em 30/08/2013.

WIKIPÉDIA. Educação Ambiental. Disponível em http://pt.wikipedia.org/wiki/Educa\%C3\%A7\%C3\%A3o ambiental. Acesso em 28/08/2013

YOUTUBE. A garota que calou o mundo por 6 minutos Eco 92 Legendado.wmv. Disponível em http://www.youtube.com/watch?v=SR1pPg1g3Ro. Acesso em 11/09/2013. 